\title{
Cirugía cosmética
}

\section{Cosmetic surgery}

\section{Dr. Carlos de Jesús Álvarez-Díaz*}

$\mathrm{L}$ a cirugía cosmética es parte inherente de la ـirugía plástica y reconstructiva que corrige o modifica partes del cuerpo para lograr un equilibrio armónico y una apariencia juvenil, que ha atrapado últimamente a un gran sector de la población. En la búsqueda de la perfección física se corre el riesgo de acudir con personal o centros de tratamiento que no cubren los estándares para realizar los procedimientos con destreza y seguridad, tema que seguiremos insistiendo.

La cirugía ha dejado de tener un fin reconstructivo-estético para convertirse en un procedimiento tendiente al rejuvenecimiento, para obtener una imagen más fresca al sentirse más atractivos, jóvenes o inclusive más seductores sexualmente, esto último con las mamoplastias de aumento y la cirugía de glúteos. También los procedimientos para pérdida de peso han au- mentado la popularidad de la liposucción para ayudar a una sociedad cada vez más obesa.

Los tratamientos faciales no se han quedado atrás y han invadido el mundo de los procedimientos estéticos con el empleo de rellenos. El rostro sigue siendo la carta de presentación de la gente y el estar en mejor forma permite ser considerado socialmente activo y atractivo, pero se debe tener en cuenta los riesgos implícitos de estos procedimientos y más si son efectuados por personal sin capacitación.

Por ello, es importante que las personas analicen estos puntos al tomar la decisión de someterse a procedimientos cosméticosreconstructivos.

\footnotetext{
Correspondencia:

Carlos de Jesús Álvarez Díaz

E-mail: cajealdi@gmail.com
} 